\title{
A Strategy Model for Assessing e-Learning and Technology Assisted Knowledge Management an Overview
}

\author{
Mehdi Asgarkhani
}

\begin{abstract}
This paper is based on the outcome of a research project intended at assessing the role e-Learning has played since the concept of e-Learning emerged. It looks at theory of benefits and values as argued by not only technologists and management but also by academics. This paper concentrates on phase I of the study - building a model for assessing impact of e-Learning. In phase II, a e-Learning projects' outcomes will be assessed by the use of the strategy model developed in phase $I$. The paper covers some of the key aspects of web-assisted learning by discussing the various stages (technologies) of technology solutions, potential benefits; the state of the e-learning industry; the barriers to introducing e-learning and building a model to assess strategic value of e-learning through web technologies
\end{abstract}

Index Terms - Knowledge management, e-Learning, webassisted learning, strategic values, strtegic model.

\section{INTRODUCTION}

Many educators and educational technologists (e.g. Baynton 2001, Rosenberg 2001, Higgins 2002, Burns et al 2001, and Dobbs 2000) believed that in early 2000 we are on the verge of a major change - where learning practices are concerned. It was argued that within the information society, the knowledge and skills that we acquire are in danger of becoming increasingly obsolete, which in turn requires us to learn on an ongoing basis. Most traditional approaches (to learning) appear to be inadequate in responding to the new challenges that are mostly focused on increased efficiency (and effectiveness) - as it concerns developing, acquiring or disseminating knowledge. The solution seems to have been provided through the application of Information and Communications Technology (ICT).

Over the past few years we have witnessed rapid advancements in ICT - which has in turn contributed towards a staggering growth in global computer networking and the emergence of a globally connected world. The Internet has evolved from being a network for researchers and academics into a platform that has enabled new businesses to find alternative ways in which to offer their products and services. We have witnessed a paradigm shift with regards to the ways in which the transfer and management of knowledge is handled. The Internet and Web-based technologies have both had a profound effect on the way(s) in which educational and training institutions now operate - in that it has made it possible for many innovative educators/trainers (within ICT enabled nations) to think of new ways in which to use the Internet in order to provide Web-based knowledge management (KM) and training opportunities.

There appears to have been significant optimism amongst

Manuscript received August 9, 2012; revised October 29, 2012.

Mehdi Asgarkhani is with the Faculty of Commerce, CPIT, Christchurch, New Zealand (email: Mehdi.asgarkhani@cpit.ac.nz). technologists and strategic planners for knowledge management - in that they view global networking and Web-based solutions as catalysts for addressing today's challenges of knowledge management (KM) and e-learning. This had become evident with an increasing number of tertiary educational institutions and industry based training organizations attempting to offer a wide variety of Web-based (online) learning solutions. These institutions have adopted a variety of strategies - some have considered Web-assisted solutions as a supplement to face-to-face communication between students and educators/trainers, whilst others have used Webbased learning through the Internet as the sole medium for delivery.

A review of e-learning cases (e.g. various cases in online learning in the Training Magazine, Asgarkhani 2003, Kiser 2001, Montanden 2002 and Rossett 2002, Pan et al 2010) in early 2000s suggests that most tertiary educational institutions and professional training organizations (within ICT enabled and globally networked countries) had acknowledged to some extent the strategic importance of using technology-based education and learning through Web-based applications. They seem to have viewed e-learning as being a fundamental and positive shift in the academic and professional knowledge management world. Yet some acknowledged that there was also a danger. If there was much emphasis on the technology aspect of e-learning and less attention given to broader issues and/or strategies, it would have been difficult to deliver futuristic solutions of a high quality. On the whole, some electronically delivered programs/courses appear to have been developed and implemented in a somewhat reactive manner, and in isolation - more specifically, without much thought being given as to strategic implications; global developments; cultural issues; digital divide and the complexity of today's knowledge management systems. As a result, some of these solutions have proved incapable of meeting the expectations of their potential markets (students/trainees).

This paper is concerned with the outcome of phase I of a research project. This phase mainly concentrates on view of literature with the intention of building a model of benefits and strategic values - at the time that the web-assisted elearning phenomenon took shape. In phase II (future research) we assess the reality of what was the basis of planning for elearning projects (perceived value models established in this paper). This paper also emphasizes the significance of a strategic foundation for driving e-learning initiatives.

\section{A PARADIGM SHIFT IN THE TRANSFER AND MANAGEMENT OF KNOWLEDGE IN EARLY 2000S: THE EVOLUTION OF E-LEARNING}

Training Magazine's 1999 statistics (Industry Report 1999) demonstrated that companies were shifting some of their 
training investments away from on-site classrooms. It appeared that in the future, changes to business, society, general attitudes towards learning and the application of technology would limit the effectiveness of traditional learning/training. Providing effective futuristic learning solutions appeared to require a shift in attitudes and perceptions - including:

1) Focussing on outcomes - Learning solutions need to make a positive impact on learners' performance and work-readiness.

2) Providing flexible access (anytime/anywhere) Knowledge solutions must meet the diverse needs of learners concerning time frames and locations.

3) Placing emphasis on online rather than paper-based delivery

4) Shifting the focus from physical facilities to networked facilities - Networked solutions for knowledge delivery (Internet or Intranet) play a significant role in information sharing, communications, and flexible access to learning material from any location in real time.

5) Facilitating real time rather than cyclic learning Today, the pace of change is extraordinary and the cycle time concerning knowledge is short. There is a need for improved learning efficiency and pace.

It has to be emphasized once again, that there is an enduring and important role for traditional classroom instruction (Asgarkhani 2003). Those who believe technology will eventually replace highly skilled teachers within classrooms of highly motivated learners are as misguided as those who consider the Internet as a phenomenon that can be overlooked as its impact will diminish over time.

E-Learning has been defined in many different ways. The historical background of e-learning can be observed over three decades of development in ICT based education and training. Various technologies (including web technologies) that have been introduced throughout the past few decades include:

1) Film

2) Advanced TV technologies and video tapes

3) Mainframe computer based "teaching machines"

4) Early microcomputers as a basis for Computer Based Training (CBT)

5) Touch screens and interactive videodisks based on "InfoWindows" hardware technology

6) Power PCs, CDs and VCDs

7) Global networking advancements and web-based solutions

Overall, universities in the US and the army appear to have played a pioneering role in the application of technology and developments which had eventually led to digital delivery of learning solutions.

Today, the e-learning industry is diverse. Numerous universities have developed profit orientated e-universities offering courses and degree programs.

The e-learning industry also includes companies that support the establishment of learning infrastructures and networks for higher education institutions (as well as corporations) - such as course management and delivery tools such as Blackboard, WebCT and Moodle that allow customers to create learning programs directly on the Web without investing in their own tools or infrastructure.
In this paper, e-learning refers to the use of Web-based technologies (and applications) in order to deliver a broad range of learning solutions - whereby learning materials can be accessed from the web or intranet via a computer and educators/trainers can communicate with each other using e-mail, chat or discussion forums. E-learning can be used as the main method of delivery of education/training or as a combined approach with face-to-face classroom-based teaching.

The key characteristics of e-learning solutions (Rosenberg 2001) were seen to be as follows:

1) Being based on computer networking technologies so as to make it capable of instant updating, storage/retrieval, distribution and sharing of instruction or information.

2) Being delivered to the learner via a computer that is connected to standard Internet technologies. However, there is much debate over the interpretation of the term "computer" and what it actually refers to.

3) Focusing on the broadest view of learning. That is to say, it considers learning solutions that go beyond the traditional paradigms of training. E-learning moves beyond training to include the delivery of information and tools that improve performance and competitiveness within the job market.

There was considerable debate in early 2000s (e.g. Dobbs 2000, Industry Report 1999, Kaeter 2000, and Kiser 2001) over the effectiveness of e-learning. Many people (e.g. Rosenberg 2001, Kushnir 2009) considered technology-based learning disappointing at its best - as they argued that its impact has been relatively minimal. Others (Kiser 2001, Dobbs 2000, and Kruse 2002a) argued that the benefits of e-learning outweighed its drawbacks.

The perceived importance of digital learning had motivated some governments to develop national guidelines and strategies for introducing e-learning solutions (e.g. New Zealand e-Learning Advisory Group 2002).

Overall, e-learning appeared to be taking root in organizations of all sizes - even though there were often different views concerning the ways in which e-learning can benefit individuals or organizations.

The International Data Corporation (IDC) and Online Learning Magazine (OLM) examined the general attitudes towards e-learning - as expressed by a group of OLM readers about training within organizations (Kiser 2001). According to this research, those people who had been responsible for the implementation of e-learning solutions seem to had been pleased with the results $(80 \%$ of the respondents used some form of e-learning and there were indications that this percentage will increase - as more than 40 percent of the respondents whose employers had not yet adopted e-learning were apparently planning to do so within the next two years). Research by the IDC showed convenience as being one of the most important reasons for employees for using e-learning.

Other studies of learners' attitudes towards e-learning within tertiary educational institutions (e.g. Burns et al 2001, Asgarkhani 2003) indicated that there was an increasing demand for web-assisted courses. A pilot study of trends and attitudes within the CPIT in Christchurch, New Zealand (Asgarkhani 2003) suggested that in general, there was an increasing interest in the application of e-learning (despite the fact that most of their learning still happened in the class- 
room). It appeared that the demand for quality web-assisted courses with multifaceted person-to-person interaction would increase rapidly in the future.

\section{Perceived BARRIERS to e-Learning: Digital DiVIDE}

Today, access to information and communication technologies (ICTs) is critical for economic and social development. Developing effective digital learning and solutions depend on the state of the ICT industry and electronic readiness (ereadiness) of countries, organizations and societies. This was discussed in early 2000 s by numerous researchers (e.g. Information Society Index 2001, OECD Workshop 2000, META Group 2000 and Asgarkhani 2002b, Kurilovas et al 2011)

Overall, it was discussed that differences in diffusion and use of ICTs and electronic networks could lead to:

1) Divides between countries

2) Social divides within countries

3) Divides within countries related to income, education, age, family type, and location

4) Business divides related to sector, region, and firm size

There was much debate over the implications of digital divide on e-learning and knowledge management. In November 2001, the global communications company Marconi (Marconi 2001) called on government and private stakeholders in South Africa to accelerate the introduction of elearning centers in remote, rural and disadvantaged areas suggesting that economic and educational benefits could have an immediate and measurable impact on poverty in South Africa. Higgins (Higgins 2002) viewed e- learning as a tool that can play a significant role in bridging the digital divide in the APEC region. However, the digital divide can also be considered as a barrier to successful rollout of e-learning solutions.

Some of the causes of digital divide that can (even today) also limit successful implementation of e-learning solutions can include:

1) Lack of telecommunications and network infrastructure

2) Limited PC access

3) Lack of financial resources for developing an infrastructure

4) Lack of ICT literacy

5) Limited Internet access

6) Cultural resistance

7) High access costs to global networks and the Internet

8) High cost of business investment

9) Strategic business impediments - applicability; the need to reorganise; the need for skills, security and privacy considerations

\section{A Strategic Value Model Perceived Benefits of E-LEARNING TO DRIVE THE PLANNING PROCESS}

As mentioned in previous sections, there was considerable debate over the potential benefits and drawbacks of webassisted learning solutions. In this section, the outcome of the review of literature (Phase I) is formulated into a strategic value model. This will become the basis of Phase II of the project - more specifically assessing to what extent these benefits actually eventuated after the implementation of elearning solutions throughout the last decade.

Some of the more obvious advantages and disadvantages of putting in place web-assisted and e-learning solutions (Asgarkhani 2003, Rosenberg 2001, Kruse 2002b, Kruse 2002c, Sitze 2001 and Burns et al 2001) are:

Benefits to solutions providers:

1) Reduced overall cost

2) Reduced learning time

3) Consistent delivery of learning material

4) Expert knowledge can be communicated and captured with effective e-learning and knowledge management systems

5) Proof of completion and certification

Benefits to learner:

1) On-demand availability

2) Self-pacing

3) Interactivity

4) Availability of newly updated material in a timely fashion

Disadvantages to solution provider:

1) The need for up-front investment

2) Technology complexities and design

3) Educators' workload

4) The need for selecting appropriate content and effective instructional design

5) Cultural acceptance

Disadvantages to learner:

1) (Learner) The need for access to technology

2) The need for printed workbooks or reference material

3) Reduced social and cultural interaction

Based on the analysis conducted on previous studies and case studies, a strategic value model for e-learning was developed. This is a two-dimensional model developed to assess the value of e-learning by considering three key strategic parameters (efficiency, effectiveness and growth). For each parameter, three functional aspects were taken into consideration (time, distance and creativity).

\section{A. Efficiency}

1) Time: Accelerating business processes and activities that are concerned with training and educating managers.

2) Distance: Reducing geographical and distance inhibitors/barriers and allowing managers in various regions to be able to participate in learning practices.

3) Creativity: Enhancing existing business processes and activities from the point of view of educators.

\section{B. Effectiveness}

1) Time: Improving the flow of information and business intelligence throughout the supply and the value chaincomponents. This facilitates both time effective delivery of learning and more profitable learning and educating processes for educators.

2) Distance: Enabling integrated control of the supply and the value chain processes. Even though this may be seen as a more business driven value and initiative, it can enhance value of educating and being educated in management courses considerable. 
3) Creativity: Enabling new (and/or modified) processes to allow innovative and more exciting methods of learning.

\section{Growth}

1) Time: Obtaining early market entry/presence for educators who are seeking internationalization.

2) Distance: Introducing new management learning products to new markets

3) Creativity: Developing new products and services that are related to educating and learning for managers.

In addition to development of the model above, there are also a number of key questions that can be considered when initiating the planning process for e-learning solutions. They are:

1) What are our reasons for pursuing digital learning?

2) Are we aware of our limitations and the challenges ahead of us?

3) What is our clear vision for digital learning?

4) What are the priorities that we have considered?

5) What types of e-learning are we ready for?

6) What specific strategies suit our choice of digital learning?

7) Do we have a methodology for selecting, planning and managing e-learning projects?

8) Did we consider a thorough plan for managing change?

9) What are the tools and metrics that we have thought of in order to be able to measure progress/success?

10) What would be a model (methodology) for managing relationships with other institutions when considering potential strategic partnerships?

11) How would our e-learning model improve the overall process of learning?

\section{CONCLUSIONS}

In early 2000s, many educators and educational technologists believe that we were about to witness a major shift in attitudes towards learning and knowledge management. The ICT and web-based solutions had fundamentally altered the technological, social and economic landscape so as to make it possible for quantum leaps to be made in the application of technology for learning.

Overall, it appeared that there had been an increasing interest in the application of e-learning within organizations. However the potential benefits of e-learning only materialize when the solutions were introduced as part of a well-planned and properly supported education/training environment.

Technical innovation on its own did not seem enough to drive the e-learning development process. More specifically, access to the right technology for delivering learning and $\mathrm{KM}$ solutions was (and is) essential but insufficient. Successful Internet-enabled (or Web-enabled) learning needs to be reliant on the development of a strategy that optimizes the application of technology through giving consideration to learning attitudes in potential markets (e.g. tertiary educational market and corporate training market); organizational culture and organizational business strategies.

Based on the analysis of the outcome of literature and case study reviews, a model for perceived benefits and strategic value of e-learning was developed. Based on the value model established in this paper, Phase II of the project will assess what did really happen? More specifically, Phase II will look at a sample of organization to assess to what extent the perceived values that formed the foundation for planning eventuated?

\section{REFERENCES}

[1] M Asgarkhani, "Strategic e-Learning and Knowledge Management," in Proceedings of the $2^{\text {nd }}$ Internationl Conference on Comuter Science Education, pp. 41-47, December 2011.

[2] M. Asgarkhani, and A. Clear, "Web-Assisted Learning: A review of Planning and Theory," in Proceedings of the 2011 CITRENZ Conference,[Online] Available: http://vwww.citrenz.ac.nzlconferences\pdflcitrenz2011.pdf.

[3] M. Asgarkhani, "Web-Technologies in Management Training: An Overview," in Proceedingsof the 2011 International Conference on Managemnt Learning and Business Technology Education, pp 41-47, May 2011.

[4] M. Asgarkhani, "Web-Assisted Teaching and Learning: A Study of Current Trends and Issues for Future Consideration," The New Zealand Journal of Applied Computing and Information Technology, vol 7, no. 1, pp7-10.

[5] M. Asgarkhani, "Strategic Management of Information systems and Technology in an e-World," in Proceedings of the 21st IT Conference - Sri Lanka, pp. 103-110.

[6] M. Asgarkhani, "e-Governance in Asia Pacific," in Proceedings of the International Conference on Governance in Asia, City University of Hong Kong.

[7] D. Baynton, "TRAINING TODAY- Online Prerequisites: The Classroom Goes Global," Training Magazine, vol. 38, no 1, January 2001.

[8] B. Boar, The Art of Strategic Planning for Information Technology, Wiley, 2001

[9] O. M. Burns, T. Case, and G. N. Dick, "Student Attitudes towards Distance Education: A Comparison of Views in Australia and the US," in Proceedings of the 12th Australian Conference on Information Systems, 2001

[10] K. Dobbs, "The State of Online Learning - What the Online World Needs Now: Quality," Training Magazine, vol. 37, no. 9, September 2000.

[11] S. Gallagher and A. Newman. (2002). Critical Success Factors to Growing Fully Online Distance Learning Programs. [Online]. Available: http://www.eduventures.com/pdf/distance.pdf

[12] J. G. Palilonis and V. Filak, "Blended Learning in the Visual Communications Classroom: Student Reflections on a Multimedia Course," Electronic Journal of E-Learning, 2009, vol 7, no. 3, pp. 247-256

[13] F. Hasanali. (2002). Critical Success Factors for Knowledge Management Systems. [Online]. Available: http://www.kmadvantage.com/docs/km_articles/Critical_Success_Fact ors_of_KM.pdf

[14] J. Heath. (2003). Creating Your e-Learning Strategy. [Online]. Available: http://www.pinneast.com/WP_creatingelearning.pdf

[15] A. Higgins. (2002). E- Learning's Role in Bridging the Digital Divide in the APEC Region. [Online]. Available: http://www.library.cqu.edu.au/conference/ presentations/Higgins.pdf

[16] C. Hsieh and Chen. (2003). Critical Success Factors for Implementing a Corporate Knowledge Management System. [Online]. Available: http://www.sbaer.uca.edu/research/2003/swdsi/Papers/050.pdf

[17] "Industry Report: 1999," Training Magazine, October 1999, pp. 40.

[18] Information Society Index (2001). ISI Countries and Ranking. [Online]

Available: http://www.worldpaper.com/2001/xjan01/ISI/2001\%20Information\%2 0Society\%20Ranking.html

[19] M. Kaeter, "The State of Online Learning-Virtual Cap and Gown," Training Magazine, vol. 37, no. 9, September 2000.

[20] K. Kiser, "The State of the Industry Report 2001," Learning Magazine, Based on a Research by the International Data Corp (IDC), October 2001.

[21] K. Kruse. (2002). Evaluating e-Learning: Introduction to the Kirkpatrick Model. [Online]. Available: http://www.elearningguru.com.

[22] K. Kruse. (2002b). The Benefits and Drawbacks of e-Learning. [Online]. Available: http://www.e-learningguru.com. 
[23] K. Kruse. (2002) Using the Web for Learning: Advantages and Disadvantages. [Online]. Available: http://www.e-learningguru.com

[24] K. Kruse. (2002) Presenting the Business Case for e-Learning. [Online]. Available: http://www.e-learningguru.com.

[25] L Kushnir, "When Knowing More Means Knowing Less: Understanding the Impact of Computer Experience on e-Learning and e-Learning Outcomes," Electronic Journal of E-Learning, vol 7, no. 3. pp. 289-300

[26] E. Kurilovas, B. Silvija, and Serikoviene, "Methodology for Evaluating Quality and Reusability of Learning Objects," Electronic Journal of E-Learning, vol 9, no. 1. pp. 39-51.

[27] Marconi ITU Report. (2001). E-Learning Needed to Bridge the Digital Divide. [Online]. Available: http://www.marconi.com/html/news/elearningneededtobridgethedigita ldivide.htm

[28] M. A. McPherson, "Organisational Critical Success Factors for eLearning Implementation," in Proceedings of the International Conference on Computers in Education (ICCE 2002), pp. 1540-1541.

[29] L. Montandon. (2002). 3 Cases of e-Learning in the Information Society. [Online].

Available: http://www.sema.es/SP/documents/elearning/

[30] META Group. (2000). The Global E-Economy Index. [Online]. Available: http://www.ecommercetimes.com

[31] New Zealand E-Learning Advisory Group, Highways and Pathways: Exploring New Zealand's E-Learning Opportunities E-Leaning Advisory Group Report, March 2002.

[32] OECD Workshop. (2000). The Digital Divide: Enhancing Access to ICTs. [Online]. Available: http://www.oecd.org/dataoecd/22/11/2428340.pdf.
[33] N. Pan, H. Lau, and W. Lai, "Sharing e-Learning Innovation across Disciplines: an Encounter between Engineering and Teacher Education," Electronic Journal of E-Learning, vol 8, no. 1, pp. 31-40.

[34] W Putzhuber, Graz University of Technology, Austria, pp. 1-12

[35] W. Robson, Strategic Management \& Information Systems - 2nd Edition, Prentice Hall, 1997.

[36] M. J. Rosenberg, e-Learning, McGraw Hill, 2001.

[37] A. Rossett, The ASTD e-Learning Handbook: Best Practices, Strategies, and Case Studies for an Emerging Field, McGraw-Hill, 2002

[38] A. Sitze, "Six Pieces of Advice on How to Evaluate a Learning Management System," E-Learning Magazine, September 2001.

[39] N. Tuncay, I. A.,Stanescu, and M. Tuncay, "A Different Vision in eLearning: Metaphors," Electronic Journal of E-Learning, 2011, vol 9, no. 1, pp. 105-114.

[40] S. Zyngier, "The Role of Technology in Knowledge Management Strategies in Australia: Recent Trends," Journal of Information \& Knowledge Management, 2003, vol. 2, no. 2, pp. 165-178.

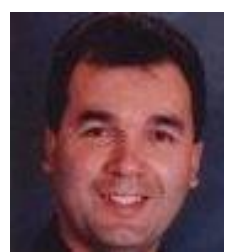

Mehdi Asgarkhani is currently a principal lecture in strategic management of ICTs and the Academic Leader (ICT qualifications) at CPIT, New Zealand Mehdi's background (both work and education) covers both ICTs and Strategic Management. He is the National Councilor representing Canterbury at IITP New Zealand. Previously, he has had various roles within the ICT sector. He holds editorial board memberships within a number of international ICT and management journals. 